\title{
Performance Evaluation of Alaoji Thermal Power Plant
}

\author{
Igbokwe J.O ${ }^{1}$, Okoro A.N ${ }^{2}$, Nwite D.C ${ }^{3}$
}

\begin{abstract}
Electricity supply in Nigeria is epileptic and characterized by extensive outages. The new NIPP plants constructed have not improved the power situation in the country. The performance of Alaoji Thermal Power Station being one of the new NIPP plants with an installed capacity of 504.4MW (consisting of $4 X 126.1 M W$ GE frame-9EA gas turbines) was studied. The study evaluated the performance of the plant for the period of January to December, 2016. The key performance indices involved were $C F, P U F, L F$, and $A F$. The required data for the analysis were obtained from the plant's operational records and personal interview of the relevant staff. The results of the study are shown in Table $1-2$ and figures $1-7$ for running hours, energy generated, load factor, availability factor, shortfall in energy generation and plant use factor respectively. When the obtained values were weighed against the international best practice of $80 \%(L F), 50$ $70 \%(P U F)$ and $95 \%(A F)$. Shortfall in energy generation ranged from $1.4 \%$ to $90.5 \%$, this is in excess of $5-10 \%$ average acceptable value. The Average PUF was $20.1 \%$, indicating that the plant was grossly underutilized during the study period. The plant had a capacity factor ranging from 7.1 - 37.5\% with an average CF of $20 \%$ for the review period. It was evident from the results that the plant performed poorly during the period under review. This was attributed to grid restrictions, insufficient gas supply and unavailability of spare parts for maintenance. It is suggested that the management should address the challenges so as to enhance the performance of the plant.
\end{abstract}

Keywords- Performance Evaluation, Generation, Thermal, Electricity, Gas Turbine.

\section{INTRODUCTION}

Power generation in Nigeria is mainly from two major sources: hydro-electric power stations and thermal (steam and gas) stations [Emovon et al., 2011]. The power facilities were managed by PHCN until it was unbundled in 2005 into 18 successor companies comprising six Generation companies, eleven Distribution Companies and one Transmission Company [Awosope, 2015]. These companies have been partially privatized except the TCN which is still wholly government controlled. Nigeria's power sector has been underperforming in spite of the huge investments in the sector over the years. Nigerians have become so accustomed to living without electricity most of the time, such that there is great jubilation whenever there is power supply by the distribution companies, albeit for a few minutes. Today, the average Nigerian only receives only three hours of electricity from the grid per day [Aina and Akinrebiyo, 2015] when power is available. No one is immune to the failings of the power sector in Nigeria commuters have now adapted to dim and sparse street lighting, businesses have factored in the impact of power losses and residences struggle to receive adequate power supply [Omontuemhen and Wijeratne, 2016]. At 126kWh per capita, if you compare that with Ghana $(361 \mathrm{kWh}, 2.9$ times higher) and South Africa(3926kWh, 31 times higher), it will be obvious that Nigeria lags far behind other developing nations in terms of grid-based electricity [NPBR, 2015]. This constant power outages and inadequate supply has negatively affected the prospects of doing business in Nigeria. To survive, most industries have to provide their own electricity, forcing most SMEs to close shop. Most multinational companies in Nigeria have either relocated their operations to their parent countries or have moved to neighbouring African countries where power supply is more reliable, thus increasing the ever growing unemployment figures in the country [Anyanwu, 2015]. Nigeria has the largest fleet of off-grid gasoline and dieselfired electricity generators in the world, estimated at $5 \mathrm{GW}$ installed capacity (Aina and Akinrebiyo, 2015), prompting Ekpo (2015) to describe the Nigerian economy as a "generator economy". In 2004, the Federal government initiated a number of NIPP plants to fast track a series of gas fired plants to adding $5 \mathrm{GW}$ to the grid - basically doubling the available fleet - these plants have failed to do so due to, among other reasons, inadequate initial planning and a shortage of gas supply [Aina \& Akinrebiyo, 2015]. The construction of these plants brought to 27 the number of grid-connected power plants in Nigeria with an installed capacity of $11,165.40 \mathrm{MW}$ with only $7,139.60 \mathrm{MW}$ available. However, the peak generation in the country has not exceeded the 5,074.7MW attained in February 2014, with Nigeria's peak electricity demand pegged at 
19,100MW (TCN, 2017). These NIPP plants are currently being managed by the Niger Delta Power Holding Company (NDPHC) pending their privatization by the federal government.

\section{ALAOJI THERMAL PLANT OVERVIEW}

Alaoji Thermal Power Plant is one of the ten NIPP plants. It is located in Alaiyi, a community near Aba in Abia State, South-Eastern Nigeria. It is proposed as a combined cycle plant with an installed capacity of 1,074MW (at ISO) on completion. However, only the phase I which is a simple cycle plant with a capacity of 504.4MW (at ISO, comprising four units of $126.1 \mathrm{MW}$ GE Frame 9EA gas turbines) is currently in operation. The second phase is still under construction. On completion, it is expected to run as a combine cycle plant with a capacity of 1074MW. The power generated by the units is evacuated through the $330 \mathrm{kV}$ Alaoji substation to the $330 \mathrm{kV}$ transmission line.

\section{METHODOLOGY}

Performance analysis was carried out on each unit and the averages used in assessing the entire plant performance. The data used were extracted from the plant's static report for 2016 obtained from the plant operator during several visits to the plant. Extensive literature survey was also done as well as personal interviews with plant management, the Operation and Maintenance team and other relevant staff. Equations $1-5$ was employed in computing the $C F, L F$, $A F$ and $P U F$ and the results are presented in Table 1 and 2 and Figures $1-7$.

Gas turbine power plant performance is affected by several factors. These factors could be environmental (ambient temperature, humidity); internal (poor maintenance, load type); or external factors (gas supply, labour strikes, acts of terrorism or war, acts of nature, grid/substation failure). All these factors together affect the output from a generating plant. The plant management only has control over the internal factors while the environmental and external factors are outside the control of plant management. In improving a system, there must first be a way to measure its current performance, compare it with the expected performance level, and then recommend it for improvement either in part or wholly if it is found to be performing below the expected output. In evaluating the performance of Alaoji thermal power plant, the following standard performance indices will be adopted: Capacity Factor (CF), Load factor (LF), Availability Factor (AF) and Plant Use Factor (PUF).
Capacity Factor $(\mathbf{C F})$ : this is a measure of the extent of use of the plant. It is the ratio of the net electricity generated for the time considered to the energy that could have been generated at full power during the same period.

$C_{f}=\frac{E_{\text {gen }}}{C_{n} \times 24 h r s \times 365 \text { days }} \times 100 \%$

Where $C_{n}$ is the nameplate capacity (MW), $E_{\text {gen }}$ is the total energy generated (MWh) for the given period.

Load Factor $\left(\boldsymbol{L}_{\boldsymbol{f}}\right)$ : This is ratio of the load that the plant draws when it is in operation to the load it could draw. It is an indication of the utilization of the plant capacity and is vital in determining the cost per unit generated.

$L_{f}=\frac{\text { Energy exported }}{\text { Installed Capacity } \times \text { Hours in month }} \times 100 \%$

Availability Factor (AF): This is defined as the fraction of a given operating period in which a generating unit is available without any outages [IEEE, 2006]. It is also defined as the percentage measure of the degree to which machinery and equipment is in an operable and committable state at the point in time when it is needed. It is mostly a factor of the plant's reliability and the periodic maintenance it requires.

$$
\begin{aligned}
& A F=\frac{A H}{P H} \\
& A F=\frac{R H+R S H}{R H+U O H+P O H}
\end{aligned}
$$

Plant Use Factor (PUF): This represents the ratio of the actual energy generated during a specified period to the product of the capacity of the plant and the number of hours the plant was in operation during the period. Since only the actual running hours of the plant is used in computing the PUF, it is thus a modification of the capacity factor of the plant [ICA, 2011].

$P U F=\frac{E_{T}}{C_{R} \times H_{R}} \times 100 \%$

$E_{T}=$ Total energy generated $(M W h)$,

$C_{R}=$ Rated or nameplate capacity $(M W)$,

$H_{R}=$ actual running hours $(H)$

\section{RESULTS AND DISCUSSION}

Data used for this study are extracted from the Plant's 2016 static report. The data collected included running hours, energy generated, energy exported, station consumption, planned outage hours, unplanned outage hours, gas interruption and grid interruptions. The results of the analysis are displayed in tables, graphs and charts below. 
Table.1: Monthly indices for LF, CF, PUF, and AF for 2016.

\begin{tabular}{|c|c|c|c|c|}
\hline Month & LF (\%) & PUF (\%) & CF (\%) & AF (\%) \\
\hline January & 37.7 & 21.5 & 37.5 & 43.8 \\
\hline February & 25 & 20.2 & 24.8 & 31 \\
\hline March & 18.1 & 17.2 & 18 & 26.3 \\
\hline April & 40.6 & 22.9 & 40.5 & 44.4 \\
\hline May & 36 & 22.6 & 35.3 & 39.9 \\
\hline June & 23.3 & 23.5 & 23.4 & 24.8 \\
\hline July & 0 & 0 & 0 & 0 \\
\hline August & 16.3 & 21.6 & 16.3 & 18.9 \\
\hline September & 11.5 & 18.5 & 11.4 & 15.5 \\
\hline Octocber & 9.8 & 29.2 & 9.7 & 8.4 \\
\hline November & 21.3 & 23.5 & 21.2 & 22.7 \\
\hline December & 7.3 & 20.7 & 7.1 & 8.8 \\
\hline
\end{tabular}

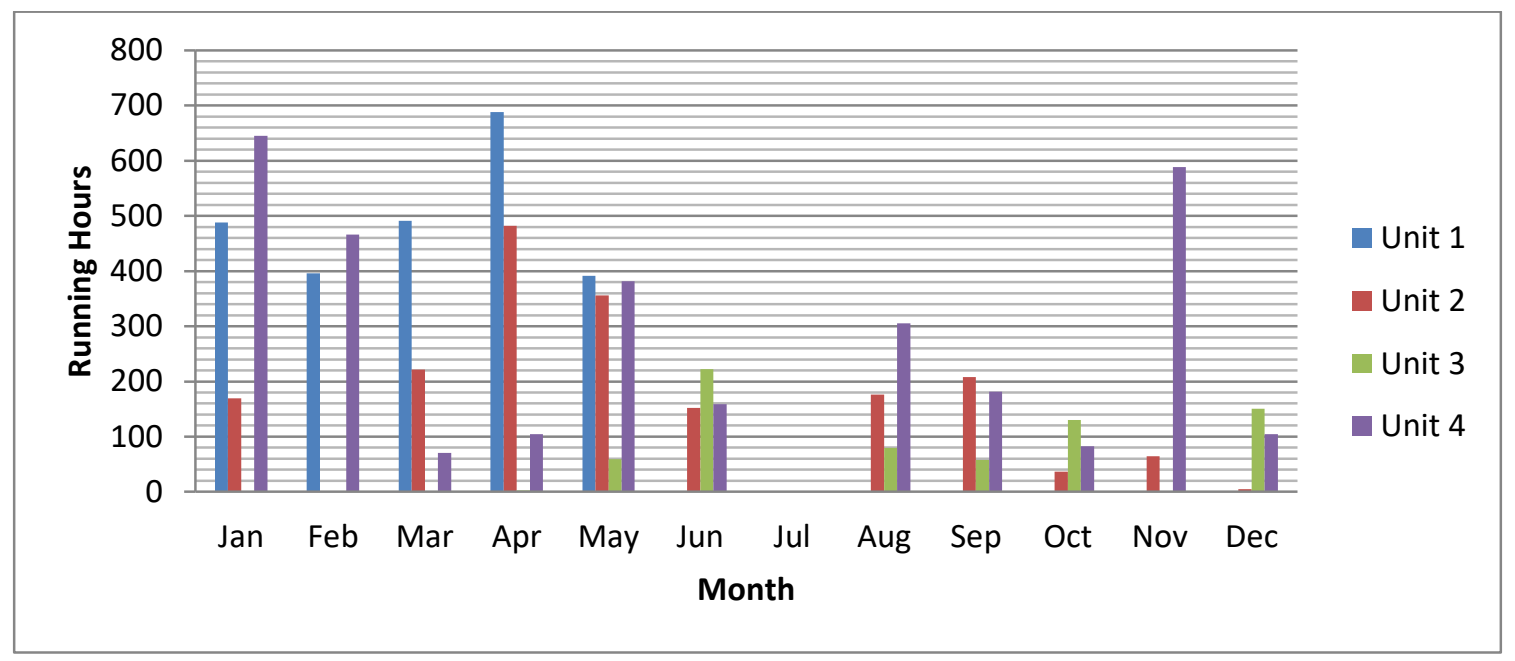

Fig.1: Showing running hours for 2016

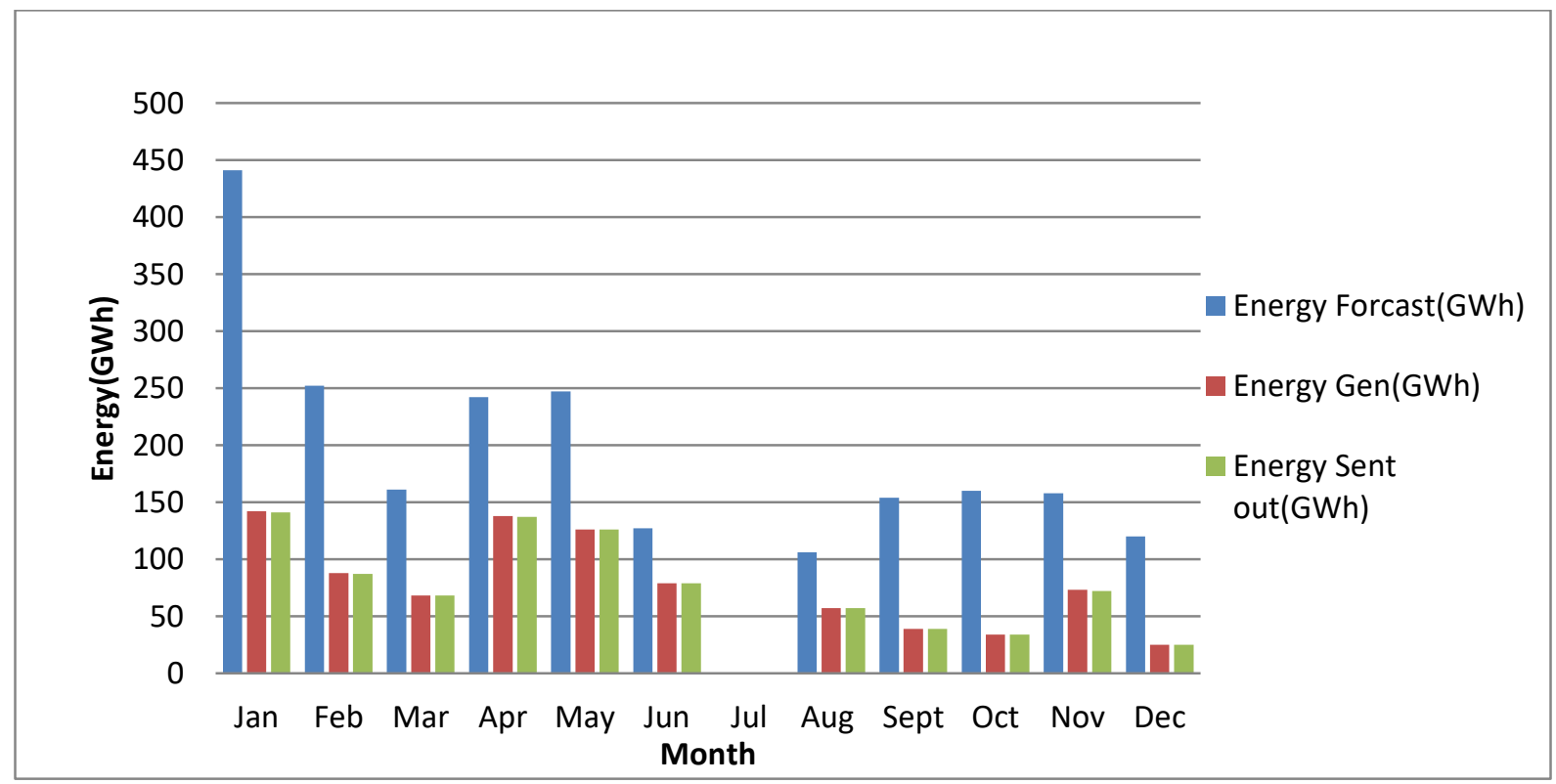

Fig.2: showing energy forecast, generated and sent out for 2016. 


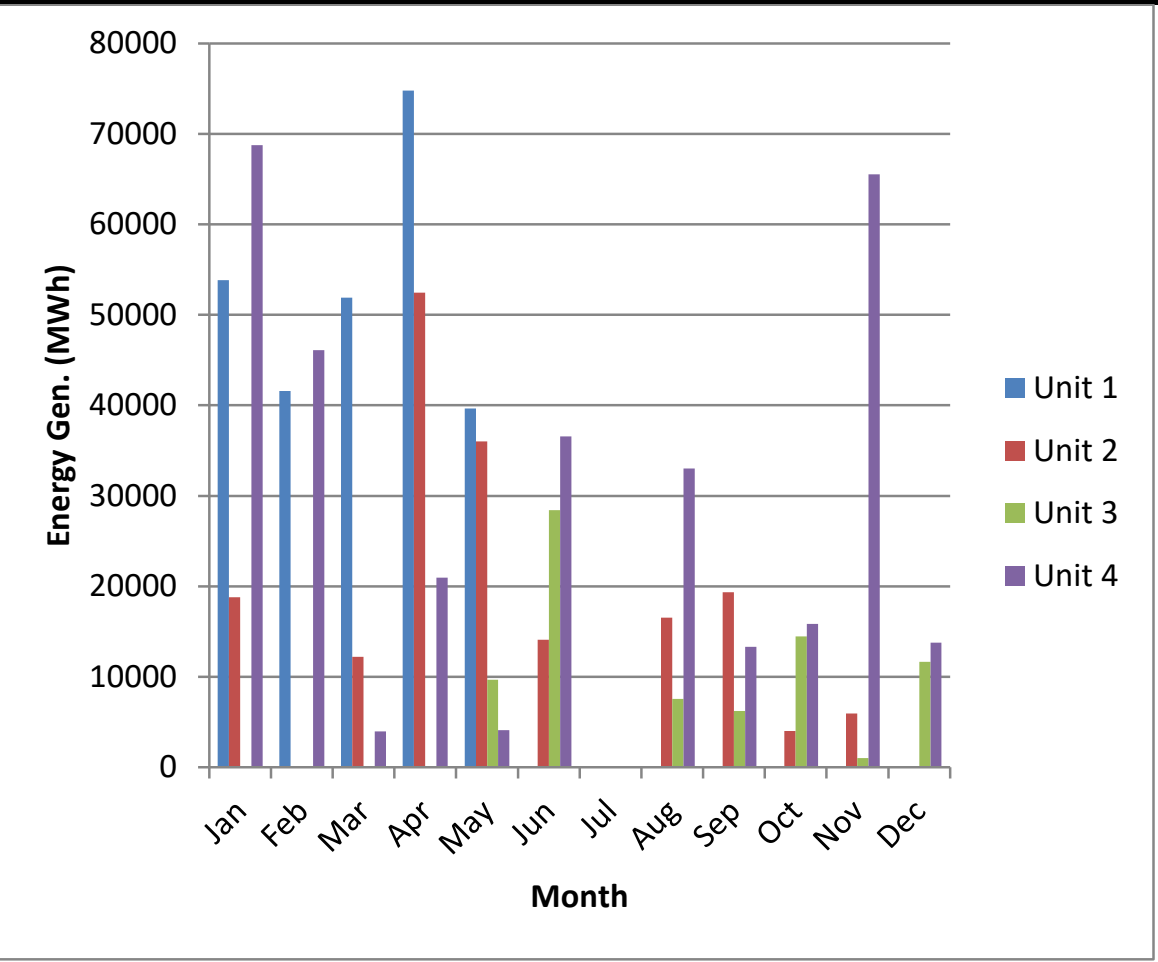

Fig.3: showing unit by unit generation for 2016

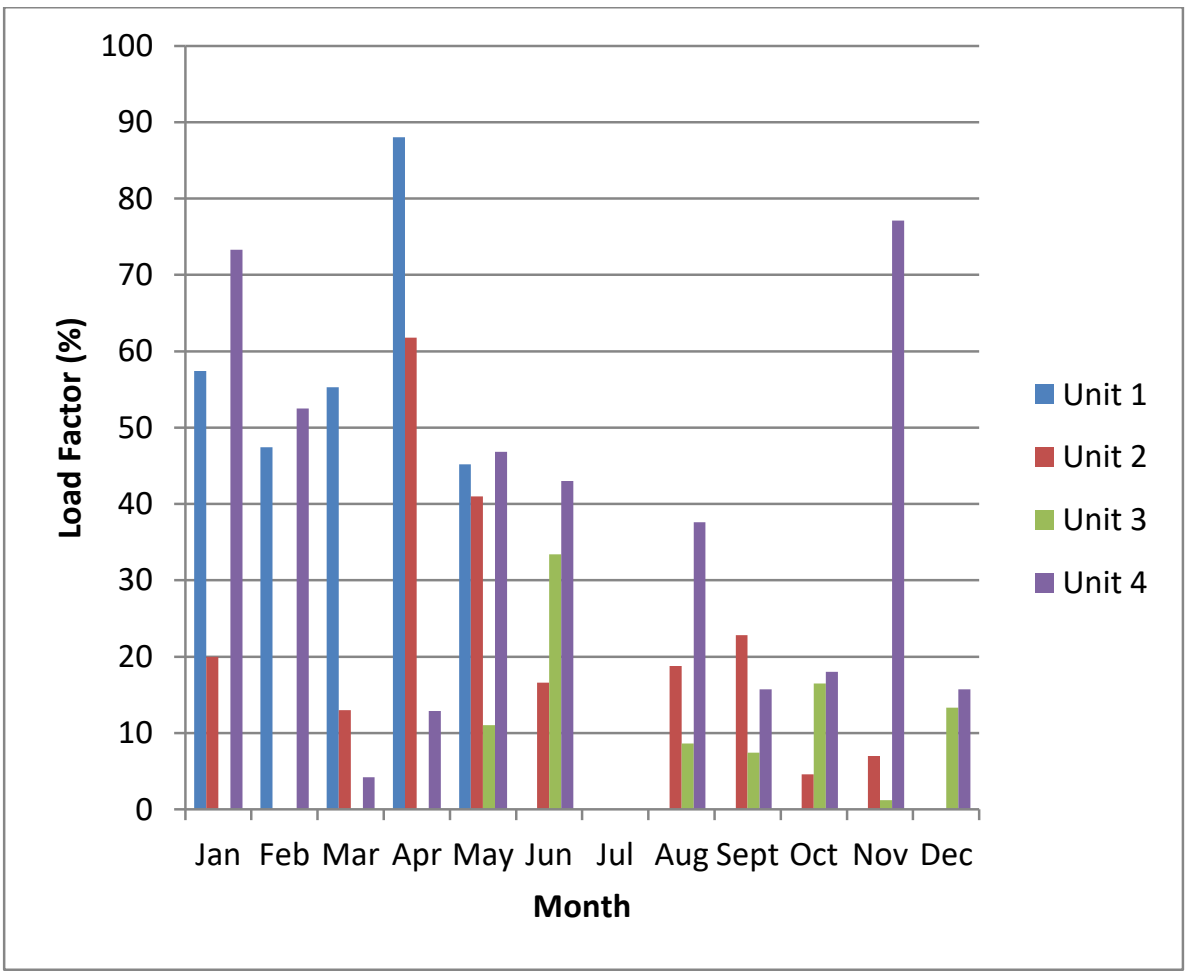

Fig.4: showing unit by unit load factor for 2016 


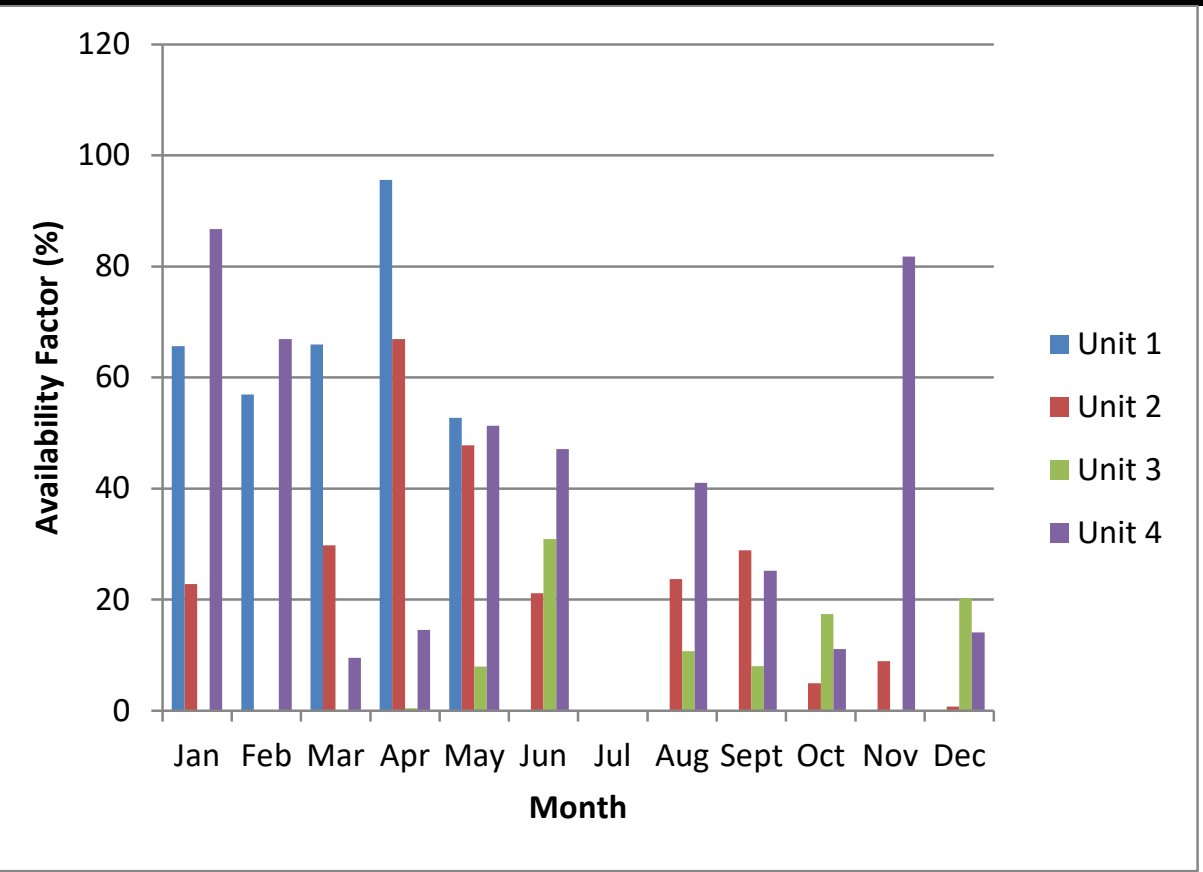

Fig.5: showing unit by unit Availability Factor for 2016.

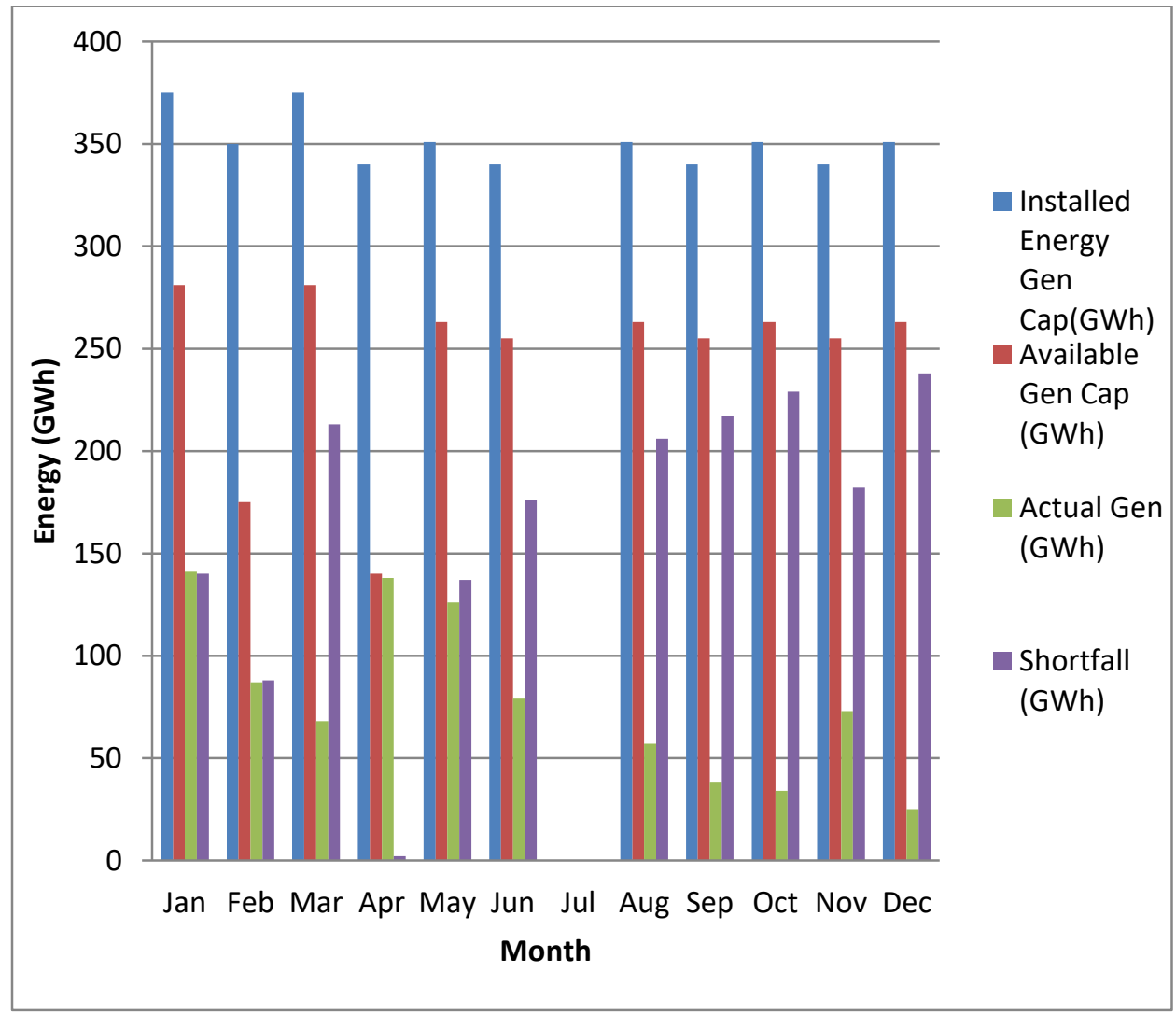

Fig.6: showing installed, Available, actual generation and shortfall in generation 


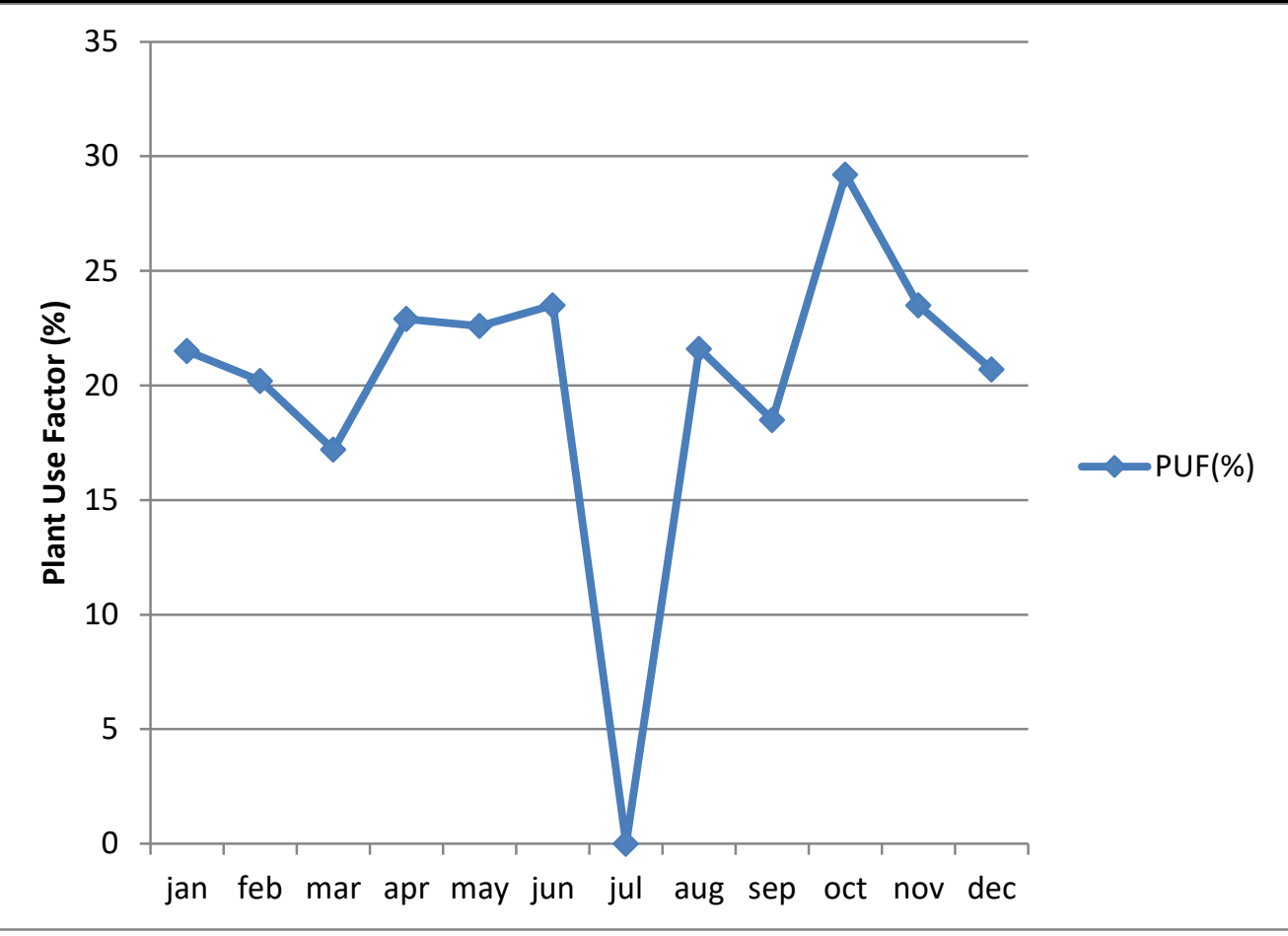

Fig.7: Showing Plant Use Factor for 2016

Table.2: Installed, Available, Actual generation and shortfall for 2016.

\begin{tabular}{|l|l|l|l|l|l|l|}
\hline Month & $\begin{array}{l}\text { Installed } \\
\text { Energy Gen } \\
\text { Cap(GWh) }\end{array}$ & $\begin{array}{l}\text { Avail. Gen } \\
\text { Cap }(\mathbf{G W h})\end{array}$ & $\begin{array}{l}\text { Actual Gen } \\
(\mathbf{G W h})\end{array}$ & $\begin{array}{l}\text { Shortfall } \\
(\mathbf{G W h})\end{array}$ & $\begin{array}{l}\text { \% } \\
\text { Shortfall }\end{array}$ & $\begin{array}{l}\text { \% } \\
\text { Available }\end{array}$ \\
\hline Jan & 375 & 281 & 141 & 140 & 49.8 & 50.2 \\
\hline Feb & 350 & 175 & 87 & 88 & 50.3 & 49.7 \\
\hline Mar & 375 & 281 & 68 & 213 & 75.8 & 24.2 \\
\hline Apr & 340 & 140 & 138 & 2 & 1.4 & 98.6 \\
\hline May & 351 & 263 & 126 & 137 & 52.1 & 47.9 \\
\hline Jun & 340 & 255 & 79 & 176 & 69 & 31 \\
\hline Jul & - & - & - & - & - & - \\
\hline Aug & 351 & 263 & 57 & 206 & 78.3 & 21.7 \\
\hline Sep & 340 & 255 & 38 & 217 & 85.1 & 14.9 \\
\hline Oct & 351 & 263 & 34 & 229 & 87.1 & 12.9 \\
\hline Nov & 340 & 255 & 73 & 182 & 71.4 & 28.6 \\
\hline Dec & 351 & 263 & 25 & 238 & 90.5 & 9.5 \\
\hline Total & $\mathbf{3 8 6 4}$ & $\mathbf{2 6 9 4}$ & $\mathbf{8 6 6}$ & $\mathbf{1 8 2 8}$ & $\mathbf{a v g = 5 9 . 2}$ & avg=32.4 \\
\hline
\end{tabular}

\section{DISCUSSION}

The installed capacity of Alaoji thermal power plant at full load is 504.4MW (i.e. 126.1MW x 4units). However, owing to the prevailing atmospheric condition in Nigeria and at the directive of the National Control Centre (NCC), the installed capacity at site ambient condition was scaled down to approximately $460 \mathrm{MW}$ (i.e. $115 \mathrm{MW} \mathrm{x} 4$ Units). The plant was commissioned for commercial operation in April 2015. Hence, the units are relatively new without any major breakdown or requiring any major maintenance.

From Figure 1, it can be seen that units 1, 2, 3, and 4 were operational for 2455.1, 1871.7, 701.6 and 3089.9 hours respectively out of a possible 8760 hours if the units were to run for every second in the year. Unit 3 had the lowest 
running hours while unit 4 was operational for the longest period during the year under review. The energy generated by each unit reflects the amount of time each unit stayed online (Figure 6, Table 2). The units generated 261,750.24, $179,470.25,79,170.86$ and $321,985.61 \mathrm{MWh}$ of energy respectively. From available data, unit 3 is seen to be the least performing, contributing only $9.4 \%$ to the total energy generated by the plant over the period. Unit-1 which had the second longest running hours and energy generated was completely down from the month of July till December because it was out on maintenance.

The shortfall in energy generation for the period under review ranges from $1.4 \%$ to $90.5 \%$ with an average of $59.2 \%$ (Table 2). This is higher when compared with 26.33$86.61 \%$ obtained by Oyedepo in his assessment of selected gas turbines (Oyedepo, 2015). It is also in excess of the average acceptable value of between $5 \%$ and $10 \%$ (ICA, 2011). It is only in the month of April, when $98.6 \%$ of the available capacity was actually generated, that the plant can be said to have performed well based on available generation capacity. The plant only generated $9.5 \%$ of its available capacity in the month of December. This is its lowest performance for the period under review, except in July when it was completely shut down due to unavailability of gas. This shows that the plant has a high level of downtime which culminates in colossal loss of revenue by the plant. This problem is blamed on gas unavailability, line restriction and poor inventory of spare parts.

From Figure 4 the plant load factor varies with each month. It ranges from $0 \%$ recorded in July 2016 to $40 \%$ recorded in April 2016, with an average of $21 \%$. Comparing this with the international best practice figure of $80 \%$ (Melodi \& Famakin, 2011), it is seen to be very low and constantly fluctuating. It is also lower than the value of $81.8 \%$ obtained by Famoriji and Adegboyega in their assessment of central gas turbine station Edjeba. The load factor gives an indication of the plant utilization. A high load factor indicates that the plant is utilized most of the time and this is desirable if the cost per unit of energy produced is to be reduced. From operation figures obtained, the load factor throughout the period of the study is less than $45 \%$ which implies that over $50 \%$ of the plant capacity was not utilized throughout the year. This ultimately increases the unit cost of energy generated, but since the cost per kilowatt of electricity is fixed in the country by NERC using the Multiyear tariff order (MYTO), the plant management does not have the luxury of unilaterally fixing the price to cover the cost of the energy they generate to enable them make maximum profit. Hence they often incur loss of revenue.
The plant use factor is shown in Figure 7. The plant has an average PUF of $20.1 \%$ with a minimum of $0 \%$ in July and peaking at $29.2 \%$ (Table 1) in the month of October for the period under study. This is low when compared with results obtained by Famoriji and Adegboyega (29.1\%) and Oyedepo (45.89-97.03\%). The ISO standard for PUF is between $50-70 \%$. This low PUF is an indication of low ratio of actual generation to expected generation. It implies that the plant is idle for a greater percentage of time throughout the year. Unavailability of gas is blamed for the most of the downtimes.

Availability factor for the four units were calculated using equation 3 and the results are tabulated and plotted in a bar chart as shown in Table 1 and Figure 5. From Fig 5, Unit-1 was only available for generation in the first four months of the year before it went out of service. Unit-2 was available all through the year although the percentage availability factor was constantly fluctuating. Unit-3 was unavailable for the months of January, February, March, July and November, and just like other units its average monthly availability factor is constantly fluctuating. Unit- 4 is seen to have the highest average availability factor of the four turbine units in the plant. The high energy generated by this unit is a reflection of its high availability factor.

\section{CONCLUSION}

Performance evaluation of Alaoji Thermal Power Plant has been carried out in this study. Based on results obtained using key performance indices, the plant had an overall poor performance. Three major reasons have been discovered to be responsible for this poor performance:

First amongst all is shortage in gas supply. Like most gas thermal plants in the country, this has been the bane to increased generation as gas supply to the plants is insufficient owing to vandalization of gas infrastructure, poor production and increasing debt profile of most of the plants to the gas companies.

Line restriction by the system operator due to poor wheeling capacity of the grid has also been found to be another major factor responsible for the poor performance of Alaoji thermal plant. The frequent partial and total collapses of the grid often experienced in the country makes it impossible for generating companies to increase their capacity without a corresponding increase in the wheeling capacity of the national grid.

Another major problem affecting the plant's performance is the unavailability of spare parts required for proper running maintenance to be carried out. There is a poor inventory of spare parts and lack of competent manpower to carry out major maintenance operations in the event of sudden 
breakdown. The availability of the units can be improved if a proper maintenance plan is drawn for the units and strictly followed.

The performance of the plant has been found to be affected not only by management, maintenance and operational practices but also by the activities of the National Control Centre, transmission and distribution companies. To improve electricity generation by Alaoji Plant there has to be an improvement in O\&M practices, provision of a robust inventory of spare parts, training and retraining of the O\&M staff to be able to carry out major maintenance activities, completing the second phase CCGT, improving gas supply, increasing the wheeling capacity of the grid, reduction in distribution losses and improved revenue collection by the distribution companies. Since the challenges facing the plant is not solely localized, it is therefore of utmost importance that all sectors of the electricity value chain be made to operate more efficiently to ensure improved electricity supply which will enhance rapid industrialization of the country and improvement in the socio-economic lives of the citizens.

\section{REFERENCES}

[1] Adegboyega, G.A and Famoriji, J.O. (2013). 'Performance Analysis of Central Gas Turbine Power Station, Edjeba, Delta State, Nigeria', International Journal of Science and Research (IJSR) India Online ISSN: 2319-7064, 2(3)

[2] Aina, Abiodun and Akinrebiyo, Femi (2015). 'Nigeria's Electric Power Sector: converting potential to reality', 2015 Africa Energy Yearbook. IFC Investing in Africa, pp: 21-25

[3] Alaoji Power Plant Statics Report 2016.

[4] Anyanwu, E. Emmanuel (2012). 'New Energy Technology Revolution: A Catalyst for Sustainable National Development', A paper delivered at the $22^{\text {nd }}$ Inaugural Lecture of the Federal University of Technology, Owerri(FUTO), Imo State. 29th October, 2012.

[5] Awosope, A. Claudius (2014). 'Nigeria Electricity Industry: Issues, Challenges and Solutions', Covenant University $38^{\text {th }}$ Public Lecture Series, 3(2).

[6] Ekpo, A. H. (2009). 'The Global Economic Crisis and the Crises in the Nigerian Economy', Presidential Address to the 50th Conference of the Nigerian Economic Society, September, Abuja-Nigeria

[7] Emovon, B., Kareem, B., and Adeyeri, M.K. (2011). 'Performance Evaluation of Egbin Thermal power Station, Nigeria', Proceedings of the World Congress on Engineering and Computer Science (WCECS), San Francisco, USA. Vol. 2, October 19-21, 2011.

[8] IEEE power Engineering Society (2006). 'IEEE Standard Definitions for Use in Reporting Electric generating Unit Reliability, Availability and Productivity' (Revision of IEEE std 762 - 1987).

[9] Infrastructure Consortium for Africa (ICA, 2011). Regional power status in African power pools report. Tunisia: African Development Bank. p. 11-12

[10] Kashim Bello (2017). 'Electricity Generation Rises to 4,303MW', Today Newspapers, $1^{\text {st }}$ April, 2017.

[11] Melodi, O. A. and Famakin, R. S. (2015). 'A Review of Solar PV-Grid Energy Cost Parity in Akure, SouthWest Nigeria', International Journal of Electrical and Computer Engineering (IJECE), 5(5): 879-886

[12] National Power Baseline Report (2015).

[13] NIPP/NDPHC. Lot 8 Alaoji Combined Cycle Power Plant System Description

[14] Okechukwu Nnodim (2017). 'Electricity generation falls by $1,450.8 \mathrm{MW}$ in two days', Punch Newspapers, published May 7, 2017. Accessed at: www.punchng.com on 7/5/2017.

[15] Omontuemhen, P. and Wijeratne, D. (2016). Powering Nigeria for the Future (2016). The power sector in Nigeria report July 2016, PwC. www.pwc.com/gmc

[16] Oyedepo, S.O, Fagbenle, R.O and Adefila, S.S (2015). 'Assessment of performance Indices of Selected Gas Turbine Power Plants in Nigeria', Energy Science and Engineering, 3(3): 239-256

[17] Oyedepo, S.O, Fagbenle, R.O, Adefila, S.S, and Adavbiele, S.A (2014) 'Performance evaluation and economic analysis of a gas turbine power plant in Nigeria', Energy Conversion and Management, 79: 431-440.

[18] PwC's Annual Power and Utilities Roundtable (2016): The challenges with transforming the Nigerian Power landscape. www.pwc.com/ng

[19] TCN daily operational report for 03/11/2017. Accessed at: http://www.nsong.org on 04/11/2017 